Pacific Journal of Mathematics

THE ORDERING STRUCTURE ON BANACH SPACES 


\title{
THE ORDERING STRUCTURE ON BANACH SPACES
}

\author{
G. A. Edgar And Junfeng ZhaO
}

Suppose $X, Y$ are Banach spaces. The binary relation $X \prec Y$ means $X=\cap T^{* *-1}[Y]$, where the intersection is taken over all bounded linear operators $T: X \rightarrow Y$. We use this definition to study sums of Banach spaces and the spaces $J\left(\omega_{1}\right), C_{\left[0, \omega_{1}\right]}$.

Introduction. In this paper we use the binary relation defined by G. A. Edgar in [5] to investigate some relationships among some sequence Banach spaces.

Notation and terminology used in this paper follow [5] and match Diestel and Uh1 [1], Dunford and Schwartz [2], Kelley [8], Lindenstrauss and Tzafriri [9]. If $X$ is a Banach space, its dual will be denoted $X^{*}$, its bidual $X^{* *}$. The subset of $X^{* *}$ canonically identified with $X$ will simply be written $X$.

In [5], G. A. Edgar established a binary relation “ $\prec$ ” for Banach spaces which is defined by

Definition. Let $X$ and $Y$ be Banach spaces. Then $X \prec Y$ means

$$
X=\bigcap T^{* *-1}[Y]
$$

where the intersection is taken over all bounded linear operators $T$ : $X \rightarrow Y$.

Let $F(X, Y)=\cap T^{* *-1}[Y] . F(X, Y)$ is called the Frame.

[5] points out that the definition can be rephrased as follows: $X \prec Y$ if and only if any $\alpha \in X^{* *}$, such that $T^{* *}(\alpha) \in Y$ for all bounded linear operators $T: X \rightarrow Y$, must be in $X$.

In this paper we use this ordering to consider the $c_{0}$-sum of Banach spaces, $l_{1}$-sum of Banach spaces and to compare them with $c_{0}$ space, $l_{1}(\Gamma)$ space respectively. We find out that under some natural conditions the ordering is preserved (see Propositions 3,5. More generally also see Proposition 4.) In this paper we also consider some function Banach spaces. We find out that the long James space, $J\left(\omega_{1}\right)$ is a predecessor of the continuous function space $C_{\left[0, \omega_{1}\right]}$ in this ordering (see Proposition 7), but $J\left(\omega_{1}\right)$ and $C_{\left[0, \omega_{1}\right]}$ both are not predecessors of $l_{\infty}$ (see Propositions $8,11)$. 
In [5] it was determined for which sets $\Gamma$ is $l_{1}(\Gamma) \prec l_{1}$. We will show that $c_{0}(\Gamma) \prec c_{0}$ for all sets $\Gamma$, but $l_{\infty}(\Gamma) \prec l_{\infty}$ only for countable sets $\Gamma$. In [5] was investigated conditions under which $\left(\oplus_{\gamma \in \Gamma} X_{\gamma}\right)_{1} \prec l_{1}$. We will investigate similar conditions for $\left(\oplus_{\gamma \in \Gamma} X_{\gamma}\right)_{0} \prec c_{0}$ and $\left(\oplus_{\gamma \in \Gamma} X_{\gamma}\right)_{0} \prec l_{\infty}$.

For any abstract set $\Gamma$, let $c_{0}(\Gamma)$ denote the Banach space of all scalar valued functions on $\Gamma$ which vanish at infinity (i.e., for which $\{\gamma$ : $|f(\gamma)|>\varepsilon\}$ is finite for any $\varepsilon>0$ ) with the norm $\|f\|=\max _{\gamma \in \Gamma}\{|f(\gamma)|\}$.

1. Proposition. Let $\Gamma$ be any abstract set, then $c_{0}(\Gamma) \prec c_{0}$.

Proof. Case (i). If $\Gamma$ is finite, then $c_{0}(\Gamma)$ is reflexive, so according to Proposition 1 [5], $c_{0}(\Gamma) \prec c_{0}$ holds.

Case (ii). Assume $\Gamma$ is infinite. Suppose $\alpha \in\left(c_{0}(\Gamma)\right)^{* *}=l_{\infty}(\Gamma), \alpha=$ $(\alpha(\gamma))_{\gamma \in \Gamma}$, but $\alpha \notin c_{0}(\Gamma)$. There is a positive number $\varepsilon_{0}>0$ such that $K_{\varepsilon_{0}}=\left\{\gamma:|\alpha(\gamma)|>\varepsilon_{0}\right\}$ is an infinite set. Choose distinct $\gamma_{n} \in K_{\varepsilon_{0}}, n=$ $1,2, \ldots$, and define an operator $T$ by $(T x)(n)=x\left(\gamma_{n}\right), n=1,2, \ldots$, where $x \in c_{0}(\Gamma)$ and $x=(x(\gamma))_{\gamma \in \Gamma \text {. }}$

Let $\left(e_{n}^{*}\right)_{n=1}^{\infty}$ be the unit vectors in $c_{0}^{*}$ and $\left(e_{\gamma}^{*}\right)_{\gamma \in \Gamma}$ be the unit vectors in $\left(c_{0}(\Gamma)\right)^{*}$. For any $x \in c_{0}(\Gamma)$,

$$
\left\langle T^{*} e_{n}^{*}, x\right\rangle=\left\langle e_{n}^{*}, T x\right\rangle=x\left(\gamma_{n}\right)=\left\langle e_{\gamma_{n}}^{*}, x\right\rangle,
$$

so $T^{*} e_{n}^{*}=e_{\gamma_{n}}^{*}, n=1,2, \ldots$, so

$$
T^{* *}(\alpha)(n)=\alpha T^{*}(n)=\left\langle\alpha, e_{\gamma_{n}}^{*}\right\rangle=\alpha\left(\gamma_{n}\right) .
$$

By the hypothesis $\left|\alpha\left(\gamma_{n}\right)\right|>\varepsilon_{0}, n=1,2, \ldots$. Therefore $T^{* *}(\alpha) \notin c_{0}$, hence $c_{0}(\Gamma) \prec c_{0}$.

Let $\Gamma$ be any abstract set, for each $\gamma \in \Gamma$, let $X_{\gamma}$ be a Banach space. Define a space by

$$
X=\left\{(x(\gamma))_{\gamma \in \Gamma}: x(\gamma) \in X_{\gamma}, \text { and for any } \varepsilon>0,\right.
$$

$$
\{\gamma:\|x(\gamma)\|>\varepsilon\} \text { is finite }\}
$$

$X$ has the norm $\|x\|=\max _{\gamma \in \Gamma}\|x(\gamma)\|, X$ is a Banach space. $X$ is called the $c_{0}$-sum of the $X_{\gamma}$ 's, written $X=\left(\oplus_{\gamma \in \Gamma} X_{\gamma}\right)_{0}$. The dual of $X$ is denoted by

$$
X^{*}=\left\{(f(\gamma))_{\gamma \in \Gamma}: f(\gamma) \in X_{\gamma}^{*} \text { and }\|f\|=\sum_{\gamma \in \Gamma}|f(\gamma)|<+\infty\right\},
$$

where $X_{\gamma}^{*}$ is the dual of $X_{\gamma}$, for each $\gamma \in \Gamma, X^{*}$ is called the $l_{1}$-sum of the $X_{\gamma}^{*}$ 's, written $X^{*}=\left(\oplus_{\gamma \in \Gamma} X_{\gamma}^{*}\right)_{1}$. The bidual of $X$ is denoted by

$$
X^{* *}=\left\{(\alpha(\gamma))_{\gamma \in \Gamma}: \alpha(\gamma) \in X_{\gamma}^{* *} \text { and }\|\alpha\|=\sup _{\gamma \in \Gamma}\|\alpha(\gamma)\|<\infty\right\},
$$


where $X_{\gamma}^{* *}$ is the bidual of $X_{\gamma}$, for each $\gamma \in \Gamma . X^{* *}$ is called the $l_{\infty}$-sum of $X_{\gamma}^{* *}$ 's, written $X^{* *}=\left(\oplus_{\gamma \in \Gamma} X_{\gamma}^{* *}\right)_{\infty}$.

For each $\gamma \in \Gamma$ define a mapping $J_{\gamma}: X_{\gamma} \rightarrow X$ by

$$
J_{\gamma} x\left(\gamma^{\prime}\right)= \begin{cases}x(\gamma) & \text { if } \gamma^{\prime}=\gamma \\ 0 & \text { if } \gamma^{\prime} \neq \gamma\end{cases}
$$

which is called the coordinate embedding (see [5]). For each $\gamma \in \Gamma$ define a mapping $P_{\gamma}: X \rightarrow X_{\gamma}$ by $P_{\gamma} x=x(\gamma)$ which is called the coordinate projection (see [5]).

Godefroy and Talagrand [7] say that a Banach space $X$ has property (X) if and only if any $\alpha \in X^{* *}$ such that $\alpha\left(\sum f_{n}\right)=\sum \alpha\left(f_{n}\right)$, for every sequence $\left(f_{n}\right) \subset X^{*}$ with $\Sigma\left|f_{n}(x)\right|<\infty$ for all $x \in X$, must be in $X$. (The $\operatorname{sum} \sum f_{n}$ is taken in the weak* topology of $X^{*}$.)

[5] proves that if $X$ is a Banach space, the $X \prec l_{1}$ if and only if $X$ has property $(X)$.

2. Proposition. Let $\Gamma$ be a set with $l_{1}(\Gamma) \prec l_{1}$. For each $\gamma \in \Gamma$, let $X_{\gamma}$ be a Banach space and $X_{\gamma}$ have Property $(X)$. Then

$$
\left(\bigoplus_{\gamma \in \Gamma} X_{\gamma}\right)_{1} \prec\left(\bigoplus_{\gamma \in \Gamma} X_{\gamma}\right)_{0}
$$

Proof. By Proposition 10 [5], for each $\gamma \in \Gamma, X_{\gamma} \prec l_{1}$ and by Proposition 15 [5], $\left(\oplus_{\gamma \in \Gamma} X_{\gamma}\right)_{1} \prec l_{1}$. Since $\left(\oplus_{\gamma \in \Gamma} X_{\gamma}\right)_{0}$ is not reflexive, it follows from Proposition 2 [5] that $l_{1} \prec\left(\oplus_{\gamma \in \Gamma} X_{\gamma}\right)_{0}$. So $\left(\oplus_{\gamma \in \Gamma} X_{\gamma}\right)_{1} \prec$ $\left(\oplus_{\gamma \in \Gamma} X_{\gamma}\right)_{0}$.

3. Proposition. Let $\Gamma$ be an abstract set and for each $\gamma \in \Gamma, X_{\gamma}$ be a Banach space with $X_{\gamma} \prec l_{1}(\Gamma)$. Then $\left(\oplus_{\gamma \in \Gamma} X_{\gamma}\right)_{1} \prec l_{1}(\Gamma)$.

The proof is very similar to the proof of Proposition 15 [5].

4. Proposition. Let $\Gamma$ be an abstract set for each $\gamma \in \Gamma$, let $X_{\gamma}, Y_{\gamma}$ be Banach spaces such that $X_{\gamma} \prec Y_{\gamma}$. Then $X \prec Y$ where $X=\left(\oplus_{\gamma \in \Gamma} X_{\gamma}\right)_{0}$, $Y=\left(\oplus_{\gamma \in \Gamma} Y_{\gamma}\right)_{0}$

Proof. Suppose $\alpha=(\alpha(\gamma))_{\gamma \in \Gamma}, X^{* *}=\left(\oplus_{\gamma \in \Gamma} X_{\gamma}^{* *}\right)_{\infty}$, but $\alpha \notin X$. There are two cases we have to consider:

1. If there is a $\gamma_{0} \in \Gamma$ such that $\alpha\left(\gamma_{0}\right) \notin X_{\gamma_{0}}$. By the hypothesis there is a linear bounded operator $T_{\gamma_{0}}: X_{\gamma_{0}} \rightarrow Y_{\gamma_{0}}$ such that $T_{\gamma_{0}}{ }^{* *} \alpha\left(\gamma_{0}\right) \notin Y_{\gamma_{0}}$. Let 
$T x=J_{\gamma_{0}} T_{\gamma_{0}} P_{\gamma_{0}}(x)$. This is a bounded linear operator from $X$ into $Y$, where $P_{\gamma}$ is a coordinate projection from $X$ into $X_{\gamma}, J_{\gamma}$ is a coordinate embedding from $Y_{\gamma}$ into $Y$. So $T^{* *}=J_{\gamma_{0}}{ }^{* *} T_{\gamma_{0}}{ }^{* *} P_{\gamma_{0}}{ }^{* *}$. So $T^{* *} \alpha=J_{\gamma_{0}}{ }^{* *} T_{\gamma_{0}}{ }^{* *} \alpha\left(\gamma_{0}\right) \notin Y$, since $T_{\gamma_{0}}^{* *} \alpha\left(\gamma_{0}\right) \notin Y_{\gamma_{0}}$.

2. Suppose $\alpha(\gamma) \in X_{\gamma}$ for all $\gamma \in \Gamma$ and there is $\varepsilon_{0}>0$ such that the set $\left\{\gamma:\|\alpha(\gamma)\|>\varepsilon_{0}\right\}$ is infinite. Suppose $\left\{\gamma_{k}\right\}_{k=1}^{\infty} \subset\left\{\gamma:\|\alpha(\gamma)\|>\varepsilon_{0}\right\}$. For each $k$ choose $f_{\gamma_{k}} \in X_{\gamma_{k}}^{*},\left\|f_{\gamma_{k}}\right\|=1$ such that $\left\langle f_{\gamma_{k}}, \alpha\left(\gamma_{k}\right)\right\rangle=\left\|\alpha\left(\gamma_{k}\right)\right\|>$ $\varepsilon_{0}$, and choose $y\left(\gamma_{k}\right) \in Y_{\gamma_{k}},\left\|y\left(\gamma_{k}\right)\right\|=1$. Now we define a linear bounded operator $T$ from $X$ into $Y$ by $(T x)(\gamma)=T_{\gamma} x(\gamma)$, for all $\gamma \in \Gamma$, where $T_{\gamma} x(\gamma)=0$, if $\gamma \neq \gamma_{k}$

$$
T_{\gamma} x(\gamma)=\left\langle f_{\gamma}, x(\gamma)\right\rangle y(\gamma), \text { if } \gamma=\gamma_{k}, k=1,2, \ldots
$$

Since the range of $T_{\gamma}$ is a finite dimensional space which is reflexive, so

$$
T_{\gamma_{k}}^{* *} \alpha\left(\gamma_{k}\right)=\left\langle f_{\gamma_{k}}, \alpha\left(\gamma_{k}\right)\right\rangle y\left(\gamma_{k}\right), \quad k=1,2, \ldots,
$$

the others $T_{\gamma}^{* *}=0$.

Let $(\bar{T} \alpha)(\gamma)=T_{\gamma}^{* *}(\alpha(\gamma)), \gamma \in \Gamma$. Now $\bar{T}$ is weak*-weak* continuous on $X^{* *}$. By definition $\left.\bar{T}\right|_{X}=T$. So $\bar{T}=T^{* *}$. According to the definition

$$
\begin{aligned}
\left\|T^{* *}(\alpha)\left(\gamma_{k}\right)\right\| & =\left|\left\langle f_{\gamma_{k}}, \alpha\left(\gamma_{k}\right) y\left(\gamma_{k}\right)\right\rangle\right| \\
& =\left\|\alpha\left(\gamma_{k}\right)\right\|>\varepsilon_{0}, \quad k=1,2, \ldots
\end{aligned}
$$

So $T^{* *} \alpha \notin Y$.

5. CoROllaRY. Let $\Gamma$ be any abstract set, for each $\gamma \in \Gamma$, let $X_{\gamma}$ be a Banach space such that $X_{\gamma} \prec c_{0}$. Then

$$
X=\left(\bigoplus_{\gamma \in \Gamma} X_{\gamma}\right)_{0} \prec c_{0} .
$$

Proof. By the hypothesis and Proposition 4 we have

$$
\left(\bigoplus_{\gamma \in \Gamma} X_{\gamma}\right)_{0} \prec\left(\bigoplus_{\gamma \in \Gamma} c_{0}(\mathbf{N})\right)_{0}=c_{0}(\mathbf{N} \times \Gamma),
$$

where $\mathbf{N}$ indicates the integers. According to Proposition 1

$$
c_{0}(\mathbf{N} \times \Gamma) \prec c_{0}
$$

is true for any $\Gamma$. So the Proposition holds.

[5] proves that if $X$ is a Banach space, then the following are equivalent.

(a) $X \prec l_{\infty}$ 
(b) If $\alpha \in X^{* *}$ is weak* continuous on all bounded weak* separable subset of $X^{*}$, then $\alpha \in X$.

We use this characterization to prove next proposition.

6. Proposition. Let $\Gamma$ be an abstract set, for each $\gamma \in \Gamma$, let $X_{\gamma}$ be a Banach space such that $X_{\gamma} \prec l_{\infty}$. Then $X=\left(\oplus_{\gamma \in \Gamma} X_{\gamma}\right)_{0} \prec l_{\infty}$.

Proof. Suppose $\alpha \in X^{* *}=\left(\oplus_{\gamma \in \Gamma} X_{\gamma}^{* *}\right)_{\infty}, \alpha=(\alpha(\gamma))_{\gamma \in \Gamma}, \alpha(\gamma) \in$ $X_{\gamma}^{* *}, \gamma \in \Gamma$ and $\sup _{\gamma \in \Gamma}\|\alpha(\gamma)\|<+\infty$. Suppose $\alpha \in F\left(X, l_{\infty}\right)$. We can claim that for any $\gamma \in \Gamma, \alpha(\gamma)$ is weak* continuous on any bounded weak* separable set $B(\gamma)$ in $X_{\gamma}^{*}$. In fact, suppose $B(\gamma)=\{f(\gamma): f(\gamma) \in$ $\left.X_{\gamma}^{*}\right\}$. Let $A=\left\{P_{\gamma}^{*} f(\gamma): f(\gamma) \in B(\gamma)\right\}$, where $P_{\gamma}^{*}$ is the adjoint operator of the coordinate projection $P_{\gamma}: X \rightarrow X_{\gamma}, \gamma \in \Gamma$. $A$ is also bounded weak* separable in $X^{*}$. Since $\alpha$ is weak* continuous on $A$, then $\alpha(\gamma)$ is also weak* continuous on $B(\gamma)$, for all $\gamma \in \Gamma$. So by Proposition 6 [5] and the hypothesis we get $\alpha(\gamma) \in X_{\gamma}$, for all $\gamma \in \Gamma$. We will show that $\alpha \in X$. Suppose $\alpha \notin X$. So there is $\varepsilon_{0}>0$ such that the set $\left\{\gamma:\|\alpha(\gamma)\|>\varepsilon_{0}\right\}$ is infinite. Let $\left\{\gamma:\|\alpha(\gamma)\|>\varepsilon_{0}\right\} \supseteq\left\{\gamma_{k}\right\}_{k=1}^{\infty}$. By the Hahn-Banach Theorem we choose $g_{\gamma_{k}} \in S\left(x_{\gamma_{k}}^{*}\right)$ such that $\alpha\left(\gamma_{k}\right)\left(g_{\gamma_{k}}\right)=g_{\gamma_{k}}\left(\alpha\left(\gamma_{k}\right)\right)=\left\|\alpha\left(\gamma_{k}\right)\right\|$, where $S\left(X_{\gamma_{k}}^{*}\right)$ is the sphere of $X_{\gamma_{k}}^{*}, k=1,2, \ldots$. Let $h_{\gamma_{k}}=P_{\gamma_{k}}^{*} g_{\gamma_{k}}, k=1,2, \ldots$, and $A_{1}=\left\{h_{\gamma_{k}}\right\}_{k=1}^{\infty} \cup\{0\} . A_{1}$ is bounded weak* separable and

$$
\begin{gathered}
h_{\gamma_{k}} \underset{k \rightarrow \infty}{\stackrel{W^{*}}{\rightarrow}} 0 . \\
\left|\alpha\left(h_{\gamma_{k}}\right)\right|=\left|\alpha\left(\gamma_{k}\right) g_{\gamma_{k}}\right|=\left\|\alpha\left(\gamma_{k}\right)\right\|>\varepsilon_{0} \underset{k \rightarrow \infty}{\rightarrow} 0=\alpha(0) .
\end{gathered}
$$

\section{Contradiction. So $\alpha \in X$.}

Suppose $\omega_{1}$ is the first uncountable ordinal number. Let $\left[0, \omega_{1}\right]$ have the order topology. $C_{\left[0, \omega_{1}\right]}$ consists of all continuous functions on $\left[0, \omega_{1}\right]$ with max norm. The dual of $C_{\left[0, \omega_{1}\right]}$ consists of all functions $f$ on $\left[0, \omega_{1}\right]$ satisfying $\|f\|=\sum_{\gamma \in\left[0, \omega_{1}\right]}|f(\gamma)|<+\infty$, written $C_{\left[0, \omega_{1}\right]}^{*}=l_{1_{\left[0, \omega_{1}\right]}}$ The bidual of $C_{\left[0, \omega_{1}\right]}$ consists of all functions $\alpha$ on $\left[0, \omega_{1}\right]$ satisfying $\|\alpha\|=$ $\sup _{\gamma \in\left[0, \omega_{1}\right]}|\alpha(\gamma)|<\infty$, written $C_{\left[0, \omega_{1}\right]}^{* *}=l_{\infty_{\left[0, \omega_{1]}\right]}}$

Let $\left[0, \omega_{1}\right]$ have the order topology. $J\left(\omega_{1}\right)$ is the James-type Banach space which consists of all of the functions $x$ on the ordinal space $\left[0, \omega_{1}\right]$ satisfying

(i) $x(0)=0$;

(ii) $x$ is continuous on $\left[0, \omega_{1}\right]$;

(iii) $\|x\|_{J}=\sup \left(\sum_{i=1}^{n}\left|x\left(\gamma_{i}\right)-x\left(\gamma_{i-1}\right)\right|^{2}\right)^{1 / 2}<+\infty$; 
the sup is taken over all finite sequences $\gamma_{0}<\gamma_{1}<\cdots<\gamma_{n}$ in $\left[0, \omega_{1}\right]$ (see [6]). $C_{\left[0, \omega_{1}\right]}$ consists of all of the continuous functions $x$ on the ordinal space $\left[0, \omega_{1}\right]$ with the norm $\|x\|=\max _{\gamma \in\left[0, \omega_{1}\right]}|x(\gamma)|$.

7. Proposition. $J\left(\omega_{1}\right) \prec C_{\left[0, \omega_{1}\right]}$.

Proof. According to [6] we know that $J^{* *}\left(\omega_{1}\right)$ can be identified with the set of all $x$ on $\left[0, \omega_{1}\right]$ satisfying (i) and (iii). Suppose $\alpha \in J^{* *}\left(\omega_{1}\right)$ but $\alpha \notin J\left(\omega_{1}\right)$. Define a bounded linear operator from $J\left(\omega_{1}\right)$ into $C_{\left[0, \omega_{1}\right]}$ by

$$
T x=x, \text { for all } x \in J\left(\omega_{1}\right) .
$$

So $T^{* *}(\alpha)=\alpha \notin C_{\left[0, \omega_{1}\right]}$. This completes the proof.

8. Proposition. $J\left(\omega_{1}\right) \nless l_{\infty}$.

In order to prove Proposition 8, we need a lemma.

9. LemMA. Suppose $A$ is a weak ${ }^{*}$ separable bounded subset in $l_{1_{\left[0, \omega_{1}\right]}}$. Then there is $a \beta \in\left[0, \omega_{1}\right)$ so that $f=0$ on $\left(\beta, \omega_{1}\right)$ for all $f \in A$.

Proof. Suppose $\left\{f_{n}\right\}$ is weak* dense in $A$. Since $f_{n} \in l_{1_{10, \omega_{1}}}$, there are at most countably many points $\left\{\gamma_{n_{j}}\right\}, j=1,2, \ldots$, so that $f_{n}\left(\gamma_{n_{j}}\right) \neq 0$ for $n=1,2, \ldots$. Since $\omega_{1}$ is uncountable ordinal number, so

$$
\sup _{j}\left\{\left\{\gamma_{n_{j}}\right\} \backslash \omega_{1}\right\}=\beta_{n}<\omega_{1}, \quad n=1,2, \ldots
$$

Let $\beta=\sup _{n}\left\{\beta_{n}\right\}$. For the same reason we get

$$
\beta<\omega_{1} \text {. }
$$

Suppose $f \in A,\left\{f_{\delta}\right\}$ is a subnet of $\left\{f_{n}\right\}$ and $f_{\delta} \stackrel{W^{*}}{\rightarrow} f$. We will show that $f=0$ on $\left(\beta, \omega_{1}\right)$. Suppose $t$ is an arbitrary point in $\left(\beta, \omega_{1}\right)$. Then

(1) If $t$ has an immediate predecessor, the characteristic function $\chi_{\{t\}} \in C_{\left[0, \omega_{1}\right]}$, so

$$
f(t)=\left\langle f, \chi_{\{t\}}\right\rangle=\lim _{\delta}\left\langle f_{\delta}, \chi_{\{t\}}\right\rangle=f_{\delta}(t)=0
$$

since $f_{\delta}=0$ on $\left(\beta, \omega_{1}\right)$ for all $\delta$.

(2) If $t$ has no immediate predecessor, then there exist $t_{n}<t, t_{n} \rightarrow t$ and $t_{n}>\beta, n=1,2, \ldots, \chi_{\left(t_{n}, t\right]} \in C_{\left[0, \omega_{1}\right]}$. (Since $\left[0, \omega_{1}\right]$ is a well-ordered set, so any element in $\left[0, \omega_{1}\right]$ has an immediate successor, so $\chi_{\left(t_{n}, t\right]} \in$ $C_{\left[0, \omega_{1}\right]}$.) So

$$
\left\langle f, \chi_{\left(t_{n}, t\right]}\right\rangle=\lim _{\delta}\left\langle f_{\delta}, \chi_{\left(t_{n}, t\right]}\right\rangle=0
$$


i.e., $\sum_{t_{n}<\gamma \leq t} f(\gamma)=\left\langle f, \chi_{\left(t_{n}, t\right]}\right\rangle=0$ for all $n$. Since

$$
\bigcap_{n}\left(t_{n}, t\right]=\{t\} \text { and }\left|f \cdot \chi_{\left(t_{n}, t\right]}\right| \leq|f| \in l_{1_{\left[0, \omega_{1]}\right.}} .
$$

Using the dominated convergence theorem we get

$$
f(t)=\sum_{\gamma=t} f(t)=\lim _{n \rightarrow \infty} \sum_{t_{n}<\gamma \leq t} f(\gamma)=\lim _{n \rightarrow \infty}\left\langle f, \chi_{\left(t_{n}, t\right]}\right\rangle=0,
$$

$f$ is arbitrary in $A$. This completes the proof.

10. Corollary. Suppose $A$ is weak ${ }^{*}$ separable bounded subset in $l_{1_{[0, \omega} \omega_{1}}$. Suppose a net $\left\{f_{\delta}\right\} \subseteq A, f \in A$. If

$$
f_{\delta} \underset{\delta}{\stackrel{W^{*}}{\rightarrow}} f
$$

then $\lim _{\delta} f_{\delta}\left(\omega_{1}\right)=f\left(\omega_{1}\right)$.

Proof. According to Lemma 9 there is a $0 \leq \beta<\omega_{1}$ so that $f=0$ on $\left(\beta, \omega_{1}\right)$ and $f_{\delta}=0$ on $\left(\beta, \omega_{1}\right)$ for all $\delta$. Since $\chi_{\left(\beta, \omega_{1}\right]} \in C_{\left[0, \omega_{1}\right]}$, so

$$
f_{\delta}\left(\omega_{1}\right)=\left\langle f_{\delta}, \chi_{\left(\beta, \omega_{1}\right]}\right\rangle, \quad f\left(\omega_{1}\right)=\left\langle f, \chi_{\left(\beta, \omega_{1}\right]}\right\rangle .
$$

Therefore $\lim _{\delta} f_{\delta}\left(\omega_{1}\right)=f\left(\omega_{1}\right)$.

Proof of Proposition 8. Recall that according to Proposition 2 [6] and Proposition 3 [6] the transfinite sequence $\left\{h_{\gamma}=\chi_{\left(\gamma, \omega_{1}\right]}\right\}_{\gamma<\omega_{1}}$ is a transfinite basis for the Banach space $J\left(\omega_{1}\right)$; the transfinite sequence $\left\{e_{\gamma}\right\}_{\gamma \in\left(0, \omega_{1}\right]}$ is a basis for the Banach space $J\left(\omega_{1}\right)^{*}$ which is the dual of $J\left(\omega_{1}\right)$, where $e_{\gamma}(x)=x(\gamma)$, for all $x \in J\left(\omega_{1}\right)$, for all $\gamma \in\left(0, \omega_{1}\right]$.

Suppose $f \in J\left(\omega_{1}\right)^{*}$. Then $f=\Sigma_{\gamma \in\left(0, \omega_{1}\right]} c_{\gamma}(f) e_{\gamma}$, where $c_{\gamma} \in J\left(\omega_{1}\right)^{* *}$ are the coordinate functionals, $J\left(\omega_{1}\right)^{* *}$ is the bidual of $J\left(\omega_{1}\right)$. Since $\left\langle e_{\gamma}, h_{\beta}\right\rangle=\chi_{\left(\beta, \omega_{1}\right]}(\gamma), \quad \beta \in\left[0, \omega_{1}\right)$, so $\sum_{\gamma \in\left(0, \omega_{1}\right]} c_{\gamma}(f)=\left\langle f, h_{0}\right\rangle$ converges. So there are at most countably many coefficients which are not zero, say $c_{\gamma_{j}}(f) \neq 0, j=1,2, \ldots$. Since $\omega_{1}$ is the first uncountable ordinal number so $\beta_{f}=\sup _{j}\left\{\left\{\gamma_{j}\right\} \backslash \omega_{1}\right\}<\omega_{1}$. So $c_{\gamma}(f)=0$, for any $\gamma \in\left(\beta_{f}, \omega_{1}\right)$.

Let $A$ be a bounded weak* separable set in $J\left(\omega_{1}\right)^{*}$. Then there is a $\beta<\omega_{1}$ so that $c_{\gamma}(f)=0$ for any $f \in A$ and for any $\gamma \in\left(\beta, \omega_{1}\right)$.

Indeed, suppose $\left\{f_{n}\right\}_{n=1}^{\infty}$ is a weak* dense in $A$. So $\beta=\sup _{n}\left\{\beta_{f_{n}}\right\}<$ $\omega_{1}$. Suppose $f \in A,\left\{f_{\delta}\right\}$ is a subnet of $\left\{f_{n}\right\}_{n=1}^{\infty}$ and

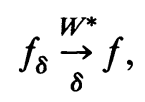

and $f_{\delta}=\sum_{\gamma \in\left(0, \omega_{1}\right]} c_{\gamma}\left(f_{\delta}\right) e_{\gamma}$, for any $\delta$.

Suppose $t \in\left(\beta, \omega_{1}\right)$. 
If $t$ has an immediate predecessor $t-1$, then $\chi_{\{t\}} \in J\left(\omega_{1}\right) \cdot \chi_{\{t\}}=$ $h_{t-1}-h_{t}$, so $\left\langle f, \chi_{\{t\}}\right\rangle=c_{t}(f),\left\langle f_{\delta}, \chi_{\{t\}}\right\rangle=c_{t}\left(f_{\delta}\right)=0$ so

$$
c_{t}(f)=\left\langle f, \chi_{\{t\}}\right\rangle=\lim _{\delta}\left\langle f_{\delta}, \chi_{\{t\}}\right\rangle=\lim _{\delta} c_{t}\left(f_{\delta}\right)=0 .
$$

If $t$ has no immediate predecessor, let $t_{n}<t, t_{n} \rightarrow t$ and $t_{n}>\beta$, $n=1,2, \ldots$, and $t_{n}$ non-limits, $\chi_{\left(t_{1}, t_{n}\right)}, \chi_{\left(t_{n}, t\right]} \in J\left(\omega_{1}\right), n=1,2, \ldots$

$$
\sum_{\gamma \in\left(t_{1}, t_{n}\right)} c_{\gamma}(f)=\left\langle f, \chi_{\left(t_{1}, t_{n}\right)}\right\rangle=\lim _{\delta}\left\langle f_{\delta}, \chi_{\left(t_{1}, t_{n}\right)}\right\rangle=0 .
$$

Similarly $\sum_{\gamma \in\left(t_{n}, t\right]} c_{\gamma}(f)=0$, for all $n$. Since $\sum_{\gamma \in\left(0, \omega_{1}\right]} c_{\gamma}(f)$ converges, so

$$
\lim _{n \rightarrow \infty} \sum_{\gamma \in\left(t_{1}, t_{n}\right)} c_{\gamma}(f)=\sum_{\gamma \in\left(t_{1}, t\right)} c_{\gamma}(f) \text {. }
$$

So

$$
\begin{aligned}
0 & =\sum_{\gamma \in\left(t_{1}, t\right]} c_{\gamma}(f)=\sum_{\gamma \in\left(t_{1}, t\right)} c_{\gamma}(f)+c_{t}(f) \\
& =\lim _{n \rightarrow \infty} \sum_{\gamma \in\left(t_{1}, t_{n}\right)} c_{\gamma}(f)+c_{t}(f)=c_{t}(f) .
\end{aligned}
$$

This shows that there is $\beta<\omega_{1}$ such that $c_{\gamma}(f)=0$ for all $f \in A$ and all $\gamma \in\left(\beta, \omega_{1}\right)$.

Since $c_{\omega_{1}}(f)=\left\langle f, \chi_{\left(\beta, \omega_{1}\right]}\right\rangle, c_{\omega_{1}}(f)=\left\langle f_{\delta}, \chi_{\left(\beta, \omega_{1}\right]}\right\rangle$, for all $\delta$. So $\lim _{\delta} c_{\omega_{1}}\left(f_{\delta}\right)=c_{\omega_{1}}(f)$.

Let

$$
\alpha(\gamma)= \begin{cases}0, & \text { if } \gamma<\omega_{1} \\ 1, & \text { if } \gamma=\omega_{1}\end{cases}
$$

$\alpha(0)=0$ and $\|\alpha\|_{J^{* *}}=1<+\infty$, so $\alpha \in J\left(\omega_{1}\right)^{* *}$. But $\alpha \notin J\left(\omega_{1}\right)$. From

$$
f_{\delta} \underset{\delta}{\stackrel{W^{*}}{\rightarrow} f}
$$

in $A$ it follows that $\lim _{\delta} c_{\omega_{1}}\left(f_{\delta}\right)=c_{\omega_{1}}(f)$. So $\lim _{\delta} \alpha\left(f_{\delta}\right)=\alpha(f)$. So $\alpha$ is weak* continuous on $A$. $A$ is any bounded weak* separable set in $J\left(\omega_{1}\right)^{*}$. By Proposition $6[5] \alpha \in F\left(J\left(\omega_{1}\right), l_{\infty}\right)$. This means that

$$
F\left(J\left(\omega_{1}\right), l_{\infty}\right) \backslash J\left(\omega_{1}\right) \neq \varnothing .
$$

So $J\left(\omega_{1}\right) \nprec l_{\infty}$.

11. Corollary. $C_{\left[0, \omega_{1}\right]} \nprec l_{\infty}$.

Proof. Suppose $C_{\left[0, \omega_{1}\right]} \prec l_{\infty}$. By Proposition 7 we have

$$
J\left(\omega_{1}\right) \prec C_{\left[0, \omega_{1}\right]} \text {. }
$$

So $J\left(\omega_{1}\right) \prec l_{\infty}$. This contradicts Proposition 8 . 
12. Corollary. Suppose $\Gamma$ is an abstract set. Then $l_{\infty}(\Gamma) \prec l_{\infty}$ if and only if $\overline{\bar{\Gamma}} \leq \aleph_{0}$.

Proof. If $\overline{\bar{\Gamma}}>\aleph_{0}$, then $C_{\left[0, \omega_{1}\right]} \prec l_{\infty}(\Gamma)$. If $l_{\infty}(\Gamma) \prec l_{\infty}$, then $C_{\left[0, \omega_{1}\right]} \prec$ $l_{\infty}$, this contradicts Corollary (11), so $l_{\infty}(\Gamma) \nprec l_{\infty}$.

The other direction is easy to check.

\section{REFERENCES}

[1] J. Diestel and J. J. Uhl, Vector measures, Math. Surveys 15, Amer. Math. Soc., 1977.

[2] N. Dunford and J. T. Schwartz, Linear operators, Part I. Interscience, 1957.

[3] G. A. Edgar, Measurability in a Banach space, Indiana Univ. Math. J., 26 (1977), 663-677.

[4] _ Measurability in a Banach space II, Indiana Univ. Math. J., 28 (1979), 559-579.

[5] __ An ordering for the Banach spaces, Pacific J. Math., 108 (1983), 83-98.

[6] , A Long James Space, In: Measure Theory, Oberwolfach, 1979, edited by D. Kolzow, Lecture Notes in Mathematics 794, Springer-Verlag, 1980.

[7] A. Godefroy and M. Talagrand, Classes d'espaces de Banach à prédual unique, C. R. Acad. Sci. Paris, 292 (1981), 323-325.

[8] J. L. Kelley, General Topology, 1955.

[9] J. Lindenstrauss and L. Tzafriri, Classical Banach Spaces I, Ergebnisse der Mathematik und ihrer Grenzgebiete 92, Springer-Verlag, 1977.

Received April 26, 1983 and in revised form December 28, 1983. This paper was written while the second author was visiting the Ohio State University.

The OHIo State University

Columbus, OHIo 43210

AND

WUHAN UNIVERSITY

Wuhan, Hubei, China 



\title{
PACIFIC JOURNAL OF MATHEMATICS EDITORS
}

\author{
DONALD BABBITT (Managing Editor) \\ University of California \\ Los Angeles, CA 90024 \\ J. DugundJI \\ University of Southern California \\ Los Angeles, CA 90089-1113 \\ R. FINN \\ Stanford University \\ Stanford, CA 94305 \\ Hermann FlaschKa \\ University of Arizona \\ Tucson, AZ 85721
}

\author{
C. C. MOORE \\ University of California \\ Berkeley, CA 94720 \\ ARTHUR OGUS \\ University of California \\ Berkeley, CA 94720 \\ Hugo Rossi \\ University of Utah \\ Salt Lake City, UT 84112 \\ H. SAMELSON \\ Stanford University \\ Stanford, CA 94305
}

\begin{tabular}{|c|c|c|c|c|}
\hline \multicolumn{5}{|c|}{ ASSOCIATE EDITORS } \\
\hline R. ARENS & $\begin{array}{l}\text { E. F. BECKENBACH } \\
(1906-1982)\end{array}$ & NeumanN & F. WOLF & K. YosHIDA \\
\hline \multicolumn{5}{|c|}{ SUPPORTING INSTITUTIONS } \\
\hline \multirow{2}{*}{\multicolumn{2}{|c|}{$\begin{array}{l}\text { UNIVERSITY OF ARIZONA } \\
\text { UNIVERSITY OF BRITISH COLUMBIA }\end{array}$}} & \multicolumn{3}{|c|}{ UNIVERSITY OF OREGON } \\
\hline & & \multirow{2}{*}{\multicolumn{3}{|c|}{ UNIVERSITY OF SOUTHERN CALIFORNIA }} \\
\hline \multirow{2}{*}{\multicolumn{2}{|c|}{$\begin{array}{l}\text { CALIFORNIA INSTITUTE OF TECHNOLOGY } \\
\text { UNIVERSITY OF CALIFORNIA }\end{array}$}} & & & \\
\hline & & \multicolumn{3}{|c|}{$\begin{array}{l}\text { STANFORD UNIVERSITY } \\
\text { UNIVERSITY OF HAWAII }\end{array}$} \\
\hline & \multicolumn{3}{|c|}{ UNIVER SITY OF TOKYO } \\
\hline \multicolumn{2}{|c|}{$\begin{array}{l}\text { MONTANA STATE UNIVERSITY } \\
\text { UNIVERSITY OF NEVADA, RENO }\end{array}$} & \multicolumn{3}{|c|}{ UNIVERSITY OF UTAH } \\
\hline \multicolumn{2}{|c|}{ NEW MEXICO STATE UNIVERSITY } & \\
\hline \multicolumn{2}{|c|}{ OREGON STATE UNIVERSITY } & \multicolumn{3}{|c|}{$\begin{array}{l}\text { WASHINGTON STATE UNIVERSITY } \\
\text { UNIVERSITY OF WASHINGTON }\end{array}$} \\
\hline
\end{tabular}

The Supporting Institutions listed above contribute to the cost of publication of this Journal, but they are not owners or publishers and have no responsibility for its content or policies.

\begin{abstract}
Mathematical papers intended for publication in the Pacific Journal of Mathematics should be in typed form or offset-reproduced (not dittoed), double spaced with large margins. Please do not use built up fractions in the text of the manuscript. However, you may use them in the displayed equations. Underline Greek letters in red, German in green, and script in blue. The first paragraph must be capable of being used separately as a synopsis of the entire paper. In particular it should contain no bibliographic references. Please propose a heading for the odd numbered pages of less than 35 characters. Manuscripts, in triplicate, may be sent to any one of the editors. Please classify according to the scheme of Math. Reviews, Index to Vol. 39. Supply name and address of author to whom proofs should be sent. All other communications should be addressed to the managing editor, or Elaine Barth, University of California, Los Angeles, California 90024.

There are page-charges associated with articles appearing in the Pacific Journal of Mathematics. These charges are expected to be paid by the author's University, Government Agency or Company. If the author or authors do not have access to such Institutional support these charges are waived. Single authors will receive 50 free reprints; joint authors will receive a total of 100 free reprints. Additional copies may be obtained at cost in multiples of 50 .
\end{abstract}

The Pacific Journal of Mathematics is issued monthly as of January 1966. Regular subscription rate: $\$ 190.00$ a year (5 Vols., 10 issues). Special rate: $\$ 66.00$ a year to individual members of supporting institutions.

Subscriptions, orders for numbers issued in the last three calendar years, and changes of address should be sent to Pacific Journal of Mathematics, P.O. Box 969, Carmel Valley, CA 93924, U.S.A. Old back numbers obtainable from Kraus Periodicals Co., Route 100, Millwood, NY 10546.

The Pacific Journal of Mathematics at P.O. Box 969, Carmel Valley, CA 93924 (ISSN 0030-8730) publishes 5 volumes per year. Application to mail at Second-class postage rates is pending at Carmel Valley, California, and additional mailing offices. Postmaster: Send address changes to Pacific Journal of Mathematics, P.O. Box 969, Carmel Valley, CA 93924.

\section{PUBLISHED BY PACIFIC JOURNAL OF MATHEMATICS, A NON-PROFIT CORPORATION}




\section{Pacific Journal of Mathematics}

\section{Vol. 116, No. 2 December, 1985}

Richard Arens, Reducing the order of the Lagrangean for a classical field in curved space-time ................................ 209

Shiferaw Berhanu, W. Wistar (William) Comfort and James Dolan Reid, Counting subgroups and topological group topologies $\ldots \ldots \ldots \ldots \ldots 217$

Michael James Cambern, Isomorphisms of spaces of norm-continuous

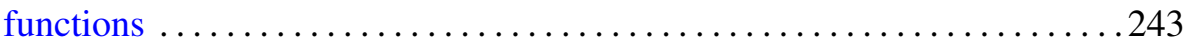

Gerald Arthur Edgar and Jun Feng Zhao, The ordering structure on

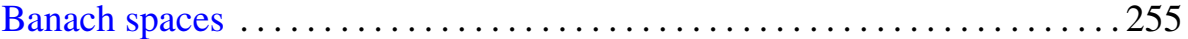

Irving Leonard Glicksberg, An analogue of Liapounoff's convexity theorem for Birnbaum-Orlicz spaces and the extreme points of their unit

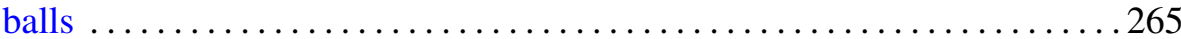

Daniel Heifetz, $p$-adic oscillatory integrals and wave front sets . ........285

José E. Pantoja, Liftings of supercuspidal representations of $\mathrm{Gl}_{2} \ldots \ldots \ldots 307$

Steven C. Pinault, An isoperimetric inequality for surfaces stationary with respect to an elliptic integrand and with at most three boundary

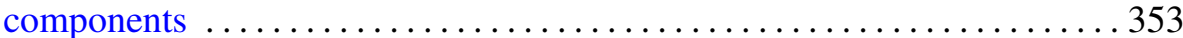

Georges Pinczon, Nonlinear multipliers and applications .............. 359 